\title{
EFEITO DA FERTILIZAÇÃO FOSFATADA NA PRODUÇÃO DE RAÍZES, LITEIRA E NODULAÇÃO DE Mimosa caesalpiniifolia BENTH ${ }^{1}$
}

\author{
Glauco Gouvêa Caldas ${ }^{2}$, Mércia Virginia Ferreira dos Santos ${ }^{3}$, Rinaldo Luiz Caraciolo Ferreira ${ }^{4}$, Mario de \\ Andrade Lira Junior ${ }^{5}$, Mario de Andrade Lira ${ }^{6}$ e Felipe Martins Saraiva ${ }^{7}$
}

\begin{abstract}
RESUMO - Este trabalho visou avaliar o efeito da adubação fosfatada sobre a nodulação, deposição de liteira e desenvolvimento do sistema radicular de $M$. caesalpiniifolia Benth, antes e depois da poda, na Estação Experimental de Itambé, da Instituto Agronômico de Pernambuco - IPA. Os tratamentos foram níveis de adubação fosfatada $\left(0,100\right.$ e $200 \mathrm{~kg} \cdot \mathrm{ha}^{-1}$ de $\left.\mathrm{P}_{2} \mathrm{O}_{5}\right)$, em delineamento com blocos casualizados com seis repetições no bloco I e sete no II, sendo o critério para formação de blocos a data do corte de uniformização. Amostragens foram realizadas antes e depois da poda da parte aérea. O comprimento, a massa seca radicular, a matéria seca de nódulos e a liteira tiveram resultados semelhantes antes e depois da poda. O número de nódulos antes da poda foi de 2, 15 e 6 nos níveis de 0,100 e $200 \mathrm{~kg} \cdot \mathrm{ha}^{-1} \mathrm{de}_{2} \mathrm{O}_{5}$ respectivamente, e 1, 6 e 7 após a poda. Comprimentos radiculares médios variaram entre 552 e $734 \mathrm{~cm}$ antes da poda e 389 e $455 \mathrm{~cm}$ após. Apenas de agosto a novembro de 2005 o número de nódulos apresentou variação, sendo observados valores de 2 a 15 nódulos antes da poda e 1 a 7 depois.
\end{abstract}

Palavras-chave: Leguminosa, nodulação e sistema radicular.

\section{EFFECTS OF PHOSPHORUS FERTILIZATION ON ROOT, LITTER AND NODULE PRODUCTION OF Mimosa caesalpiniifolia}

\begin{abstract}
This work aimed to evaluate the effect of phosphorus fertilization on nodulation, litter deposition and root system development of M. caesalpiniifolia Benth, before and after pruning, at the Itambé Experimental Station of Pernambuco Agronomical Institute - IPA in Pernambuco, Brazil. Treatments were levels of phosphorus fertilization $\left(0,100\right.$ and $200 \mathrm{~kg}$.ha ${ }^{-1}$ of $\left.P_{2} \mathrm{O}_{5}\right)$ arranged in a randomized block design with six replicates in block I and seven in block II, with the criterion for block formation being uniformization cut date. Samplings were taken before and after pruning of the aerial part Root length and root, nodule and litter dry matter had similar results before and after pruning. Nodule numbers before pruning were 2, 15 and 6 for 0,100 and $200 \mathrm{~kg} . \mathrm{ha}^{-1}$ of $\mathrm{P}_{2} \mathrm{O}_{5}$, respectively, and 1, 6 and 7 after pruning. Average root lengths ranged from 552 to $734 \mathrm{~cm}$ before and from 389 to $455 \mathrm{~cm}$ after pruning. The number of nodules presented variation only from August to November 2005, with values from 2 to 15 and from 1 to 7 nodules, before and after pruning, respectively.
\end{abstract}

Keywords: Legume, nodulation and root system.

\footnotetext{
${ }^{1}$ Recebido em 24.04.2007 e aceito para publicação em 06.03.2009.

${ }^{2}$ Escola Agrotécnica Federal de Barreiros, Barreiros-PE. E-mail: <glauco.caldas@ hotmail.com>.

${ }^{3}$ Departamento de Zootecnia da Universidade Federal Rural de Pernambuco (UFRPE). Bolsista CNPq. E-mail: <mercia@dz.ufrpe.br>.

${ }^{4}$ Departamento de Ciência Florestal da UFRPE, Recife-PE. Bolsista CNPq. E-mail: <rinaldo@ dcfl.ufrpe.br>.

${ }^{5}$ Departamento de Agronomia da UFRPE, Recife-PE. Bolsista CNPq. E-mail: <mario.lira@ depa.ufrpe.br>.

${ }^{6}$ Instituto Agronômico de Pernambuco (IPA), Recife-PE. E-mail: <mariolira@ terra.com.br>.

${ }^{7}$ Programa de Pós-Graduação em Zootecnia da UFRPE. E-mail: <felmart@ @lick21.com.br>.
} 


\section{INTRODUÇÃO}

Sabiá, sabiazeiro, sansão do campo ou unha-degato (Mimosa caesalpiniifolia Benth) é uma leguminosa tropical arbórea de pequeno porte que chega até $7 \mathrm{~m}$ de altura, nativa da Região Nordeste, sendo encontrada do Maranhão a Pernambuco (VASCONCELOS et al., 1984). Essa espécie propaga-se por sementes (ALVES et al., 2004), sendo promissora para reflorestamento devido à resistência à seca, precocidade, madeira resistente à umidade, excelente para estacas, lenha e carvão e de fácil renovação (LORENZI, 2000), rápido crescimento (ALMEIDA et al., 1986) e alto teor proteico (ALMEIDA et al., 2006).

O nível de fertilidade dos solos é um dos fatores que determinam a produção de forragem, especialmente das leguminosas. O fósforo é um dos nutrientes com maior deficiência em solos tropicais e, conforme Resende et al. (1999), essencial para o desenvolvimento vegetal de espécies pioneiras.

A acidez do solo e as deficiências nutricionais são as principais limitações ao desenvolvimento de espécies arbóreas em solos com baixa fertilidade (GONÇALVES et al., 1999). O uso de leguminosas, em áreas degradadas, adiciona, relativamente, em pouco tempo, grande quantidade de matéria orgânica e $\mathrm{N}$ por meio da produção de liteira, favorecendo a ciclagem de nutrientes e o processo de recuperação (COSTA et al., 2004).

A grande maioria das espécies florestais, quando em sua fase inicial de desenvolvimento, necessita de maior suprimento de fósforo pelo reduzido desenvolvimento do sistema radicular. Por isso, as leguminosas dependem da simbiose como fonte de nitrogênio e necessitam de altas quantidades de fósforo no solo para suprir a necessidade dos nódulos.

O uso de leguminosas melhora a qualidade da dieta animal, pela presença de nódulos que aumentam o suprimento de $\mathrm{N}$, contribuindo para melhoria na produção. Assim, o objetivo deste trabalho foi estudar a influência de adubação fosfatada na nodulação, deposição de liteira e sistema radicular da sabiá, antes e após a poda.

\section{MATERIAL E MÉTODOS}

O experimento foi realizado na Estação Experimental de Itambé, do Instituto Agronômico de Pernambuco (IPA), $07^{\circ} 25^{\prime}$ de latitude sul e $35^{\circ} 06^{\prime}$ de longitude oeste, no Município de Itambé, Pernambuco. A vegetação regional dessa área é classificada como Floresta Caducifólia e Subcaducifólia, formação arbustivo-arbórea, com várias espécies de considerável valor forrageiro. A precipitação média anual é de aproximadamente 1.200 mm (Figura 1), com temperatura média anual de $24^{\circ} \mathrm{C}$ e altitude aproximada de 190 m (CPRH, 2003).

O solo da Estação Experimental de Itambé, PE (JACOMINE, 2001), é classificado como Argiloso Vermelho-Amarelo. Foi retirada uma amostra de solo composta de 20 amostras simples da área para a realização da análise química a 0-20 e 20-40 cm de profundidade, antes da aplicação dos tratamentos (Tabela 1), indicando teores baixos de fósforo. $\mathrm{Na}$ final do experimento foi retirada uma amostra de solo composta de 20 amostras simples, em ambos os blocos, para realização de análises de fertilidade e físicas, a uma profundidade de 0-20 $\mathrm{cm}$. As análises foram realizadas nos Laboratórios de Fertilidade e Física do Solo da Universidade Federal Rural de Pernambuco (UFRPE).

O experimento foi realizado em um plantio com aproximadamente 13 anos, com espaçamento de 3,0 x 3,0 m entre plantas, área de 0,3 ha, 210 plantas, em dois blocos. Um corte de uniformização foi realizado a $50 \mathrm{~cm}$ do solo, em maio e junho de 2004, para formação dos blocos com seis e sete repetições internas. A parcela experimental foi formada por uma planta em uma área de $9 \mathrm{~m}^{2}$ circundada por oito plantas competitivas.

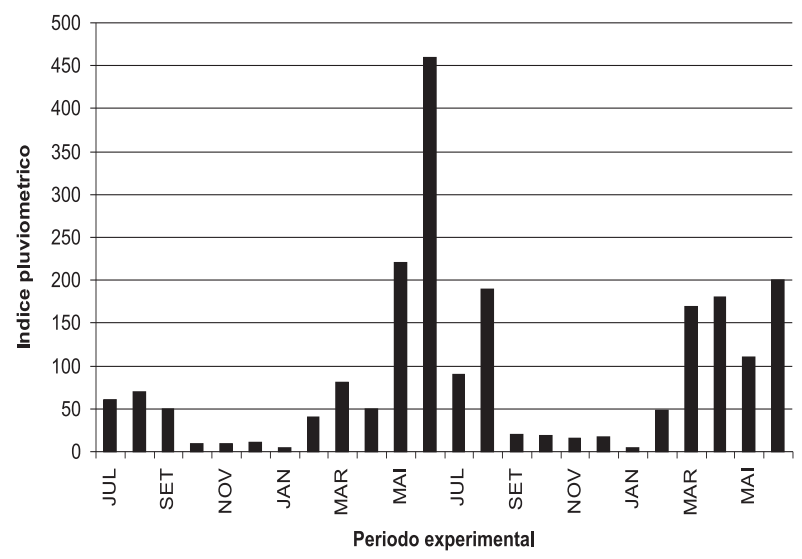

Figura 1 - Índice pluviométrico da área durante o período experimental, julho de 2004 a junho de 2006, em Itambé, PE.

Figure 1-Rain precipitation from July 2004 to June 2006 in Itambé-PE. 
Tabela 1 - Análise de fertilidade do solo em diferentes profundidades, na área experimental antes da aplicação dos tratamentos, em Itambé,PE

Table 1 - Soil fertility analysis at different depths in the experimental area, before treatment application, Itambé-PE

\begin{tabular}{ccccccc}
\hline Profundidade $(\mathrm{cm})$ & $\mathrm{pH}$ (água 1:2,5) & $\mathrm{P}\left(\mathrm{mg} \cdot \mathrm{dm}^{-3}\right)$ & $\mathrm{K}$ & $\mathrm{Ca}^{2+}+\mathrm{Mg}^{2+}$ & $\mathrm{Ca}^{2+}$ & $\mathrm{Al}^{3+}$ \\
\cline { 3 - 6 } & & & & \multicolumn{2}{c}{$\left(\mathrm{cmolc}^{2+} \mathrm{dm}^{-3)}\right.$} & \\
\hline $0-20$ & 4,90 & 7 & 0,51 & 4,10 & 2,7 & 0,6 \\
$20-40$ & 4,97 & 6 & 0,25 & 3,75 & 2,5 & 0,5 \\
\hline
\end{tabular}

Os tratamentos foram em três níveis de adubação fosfatada $\left(0,100,200 \mathrm{~kg} \cdot \mathrm{ha}^{-1}\right.$ de $\left.\mathrm{P}_{2} \mathrm{O}_{5}\right)$, fornecidos na forma de superfosfato simples. A adubação foi realizada ao redor da planta experimental na superfície do solo numa única aplicação, logo após o corte de uniformização.

O solo e a liteira foram coletados nos dias $10 \mathrm{e}$ 26 de agosto nos blocos I e II, respectivamente, antes da poda da parte aérea, e 17 de outubro e 28 de novembro nos blocos I e II, correspondendo ao período após a poda. A poda da parte aérea consistiu na retirada das folhas e de ramos com diâmetro máximo de $5 \mathrm{~mm}$ até $2 \mathrm{~m}$ do solo.

A massa de liteira foi retirada ao redor da planta experimental em área de 10x15 cm do solo, sendo pesada e seca em estufa.

Quatro amostras de solo foram coletadas por planta a $25 \mathrm{~cm}$ da extremidade da touceira, retirando-se o solo de uma superfície de 10 x 15 x $10 \mathrm{~cm}$ (largura, comprimento e profundidade), com cavador. As amostras de solo foram passadas em peneira de $5 \mathrm{~mm}$ de malha para retirar as raízes, sendo os nódulos separados, manualmente, com pinça, contados e colocados em estufa de circulação forçada a $65^{\circ} \mathrm{C}$ por $72 \mathrm{~h}$.

Todas as ramificações das raízes que ficaram acima da peneira foram medidas com trena, após a retirada dos nódulos. O comprimento das raízes foi representado por todos os valores somados. A matéria seca das amostras de raízes e nódulos foi determinada por pesagem após a secagem em estufa de circulação forçada a $65^{\circ} \mathrm{C}$ por $72 \mathrm{~h}$.

Os dados obtidos foram analisados com o SAS, versão 8.0 (SAS, 1999), sendo realizado teste de homogeneidade para a presença de nódulos, pelo teste $\chi^{2}$, pois grande parte das amostras não os apresentaram. Todos os dados foram avaliados para homogeneidade da variância e normalidade da distribuição, através do PROC Guided Data Analysis do SAS, com as transformações por ele sugeridas. O teste de Tukey a 5\% de probabilidade foi utilizado para comparação das médias.

\section{RESULTADOS E DISCUSSÃO}

Os tratamentos de fósforo não afetaram as características físicas e de fertilidade do solo (Tabelas 2 e 3). $\mathrm{O}$ pH do solo e os teores de fósforo foram superiores no bloco II, mas isso não ocorreu quanto ao teor de matéria orgânica do solo. Isso provavelmente se deve ao fato de o solo do bloco I apresentar textura mais argilosa, o que contribui para a manutenção da matéria orgânica e maior capacidade de retenção de água, fatores que favorecem a atuação dos microrganismos.

Tabela 2 - Análise física de amostras do solo, conforme os níveis de adubação fosfatada nos diferentes blocos ao final do experimento, em Itambé, PE

Table 2 - Physical analysis of soil samples according to phosphorus fertilization levels in the different blocks at the end of the experiment, Itambé-PE

\begin{tabular}{|c|c|c|c|c|c|c|c|c|c|c|}
\hline \multirow[t]{2}{*}{ Bloco } & \multirow[t]{2}{*}{$\mathrm{kg} \mathrm{P}_{2} \mathrm{O}_{5} \mathrm{ha}^{-1}$} & \multicolumn{3}{|c|}{$\begin{array}{c}\text { Composição } \\
\text { Granulométrica } \\
(\%)\end{array}$} & \multirow[t]{2}{*}{$\begin{array}{c}\text { Classificação } \\
\text { Textural }\end{array}$} & \multirow[t]{2}{*}{$\begin{array}{c}\text { Densidade do } \\
\text { Solo } \\
\left(\mathrm{g} . \mathrm{cm}^{-3}\right)\end{array}$} & \multirow[t]{2}{*}{$\begin{array}{c}\text { Porosidade } \\
\text { Total } \\
(\%)\end{array}$} & \multicolumn{2}{|c|}{$\begin{array}{c}\text { Capacidade de } \\
\text { Retenção } \\
\text { de Água }\end{array}$} & \multirow{2}{*}{$\begin{array}{c}\text { Condutividade } \\
\text { Hidraúlica } \\
\left(\mathrm{cm} \cdot \mathrm{h}^{-1}\right)\end{array}$} \\
\hline & & Areia & Argila & Silte & & & & $1 / 3 \mathrm{~atm}$ & $15 \mathrm{~atm}$ & \\
\hline I & 0 & 60,2 & 23,8 & 16,0 & $\begin{array}{l}\text { Franco- Argilo } \\
\text { - Arenoso }\end{array}$ & 1,17 & 53,7 & 16,1 & 5,12 & 21,5 \\
\hline I & 100 & 62,2 & 23,8 & 14,0 & $\begin{array}{l}\text { Franco-Argilo } \\
\text { - Arenoso }\end{array}$ & 1,25 & 50,6 & 17,8 & 10,1 & 7,2 \\
\hline I & 200 & 60,2 & 25,8 & 14,0 & $\begin{array}{l}\text { Franco- Argilo } \\
\text { - Arenoso }\end{array}$ & 1,20 & 52,6 & 17,3 & 9,9 & 3,8 \\
\hline II & 0 & 70,6 & 14,8 & 15,0 & Franco- Arenoso & 1,42 & 44,5 & 8,5 & 4,4 & 10,4 \\
\hline II & 100 & 74,2 & 14,8 & 11,0 & Franco- Arenoso & 1,46 & 42,9 & 10,0 & 4,1 & 25,1 \\
\hline II & 200 & 66,2 & 21,8 & 12,0 & $\begin{array}{l}\text { Franco- Argilo } \\
\text { - Arenoso }\end{array}$ & 1,33 & 47,4 & 8,13 & 3,2 & 6,0 \\
\hline
\end{tabular}

R. Árvore, Viçosa-MG, v.33, n.2, p.237-244, 2009 
Tabela 3 - Análise de fertilidade do solo de acordo com o nível de adubação ao final do experimento, em Itambé, PE Table 3 -Soil fertility analysis according to fertilization levels at the end of the experiment, Itambé-PE

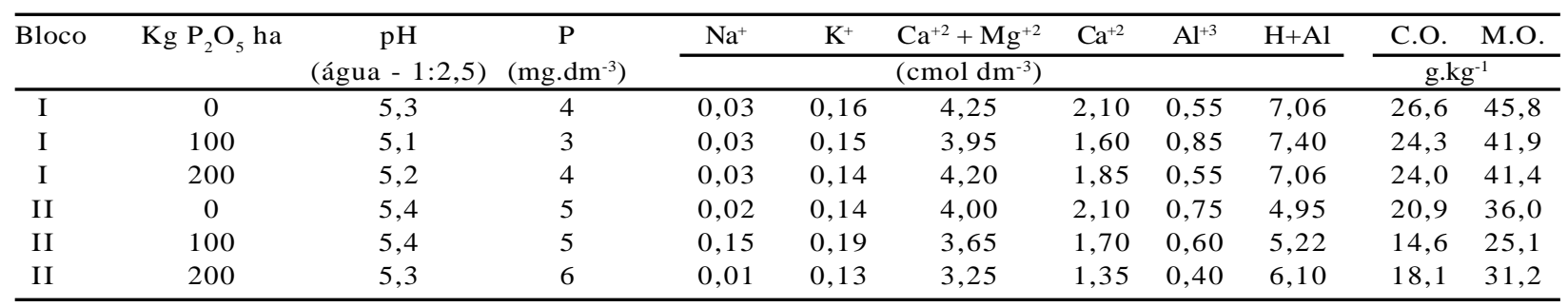

A densidade do solo foi maior no bloco II, com média de 1,40 g.cm ${ }^{-3}$; valor esse considerado alto, embora não comprometa a respiração e crescimento das raízes, e no bloco I foi observado ser de 1,20 g. $\mathrm{cm}^{-3}$ (Tabela $3)$. No entanto, a maioria das culturas é afetada por densidade de solo acima de $1,50 \mathrm{~g} . \mathrm{cm}^{-3}$, pela falta de $\mathrm{O}_{2}$ para a respiração das raízes, devido à baixa porosidade e à má drenagem e por impedimento mecânico para o crescimento das raízes, limitando-se a zona de absorção de água e nutrientes (SOUZA et al., 1997).

A porosidade total do bloco II foi menor, com média de 44,98\%, isso por estar relacionada à maior densidade do solo no bloco I, com porcentual de 52,30\%.

O número de plantas com presença de nódulos foi reduzido (Tabela 4). A presença ou ausência de nódulos não foi afetada pela adubação fosfatada, com a variabilidade, apesar de alta, sendo relativamente comum em trabalhos de levantamento de nodulação em espécies arbóreas no campo (DULORMNE et AL., 2003; WOLDE-MESKEL etAL., 2004; DIABATE et AL., 2005; GROSSMAN et AL., 2006, entre outros). O processo de nodulação em leguminosas em viveiros no Sul de
Minas Gerais (BARBERI et., 1998) apontou que ausência de nodulação pode estar relacionada a fatores químicos do solo (acidez, deficiência de P, Mo, Co etc.), físicos (compactação, erosão, salinização etc.), ou biológicos (ausência de estirpes específicas) ou, ainda, o estágio de desenvolvimento da planta. Como as plantas estudadas estavam em bosque já estabelecido e maduro, é possível que parte do efeito seja devido à maturidade das plantas com sistema radicular bastante desenvolvido e pela influência da época de realização da poda, bem como possivelmente devido ao fato de a amostragem ter sido realizada próxima ao caule, para permitir a certeza da identificação da planta responsável pelos nódulos, enquanto os nódulos poderiam estar presentes em pontos mais afastados do sistema radicular (MOREIRA e PEREIRA, 2001; MOREIRA, 2006).

A maior presença de nódulos antes da poda provavelmente está associada ao efeito marcante da desfolha da parte aérea no sistema radicular da planta. Após a desfolha, a planta mobiliza suas reservas para novas brotações, diminuindo o desenvolvimento da parte subterrânea.

Tabela 4 - Número de plantas com a presença ou ausência de nódulos, de acordo com a dosagem de fósforo e realização da poda, em Itambé, PE

Table 4 -Number of plants with or without nodules, according to P fertilization level and pruning, Itambé-PE

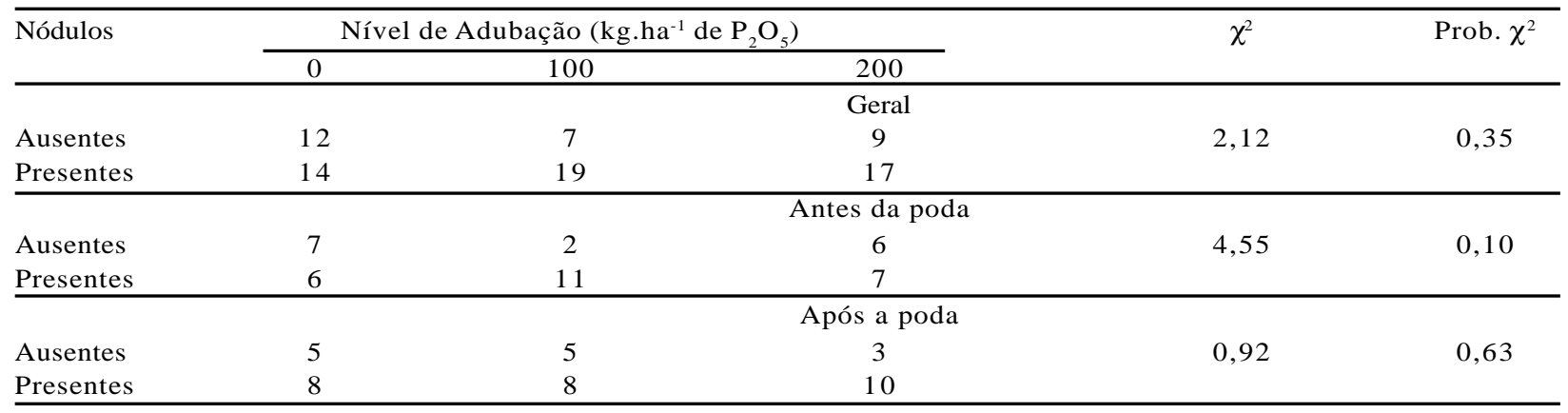

R. Árvore, Viçosa-MG, v.33, n.2, p.237-244, 2009 
A adubação fosfatada não influenciou o comprimento, massa seca de raiz e massa de liteira (Tabela 5), o que pode ser devido à forma e época de aplicação do fertilizante. A aplicação a lanço pode ter diluído o fertilizante no solo, e o longo tempo de permanência do adubo em contato com a liteira pode ter aumentado a adsorção de fósforo.

O comprimento de raízes variou de 655 e 431 $\mathrm{cm}$ antes da poda e 409 a $454 \mathrm{~cm}$ depois desta. A dificuldade de separar as raízes do solo pode ter reduzido a precisão e aumentado o erro experimental, contribuindo para a ausência de diferenças, como relatado em estudos com três leguminosas anuais (Trifolium resupinatum $\mathrm{L}$., Trifolium subterraneum L. e Lotus subbiflorus Lag.) de estação fria submetidas à adubação fosfatada e potássica (KROLOW et al., 2004).

Na massa de liteira antes e após a poda, não foi observado efeito da adubação fosfatada, com valores de 86 e 68 t/ha nos níveis 100 e 200 kg.ha ${ }^{-1}$ de $\mathrm{P}_{2} \mathrm{O}_{5}$, respectivamente. Ressalte-se que a recomendação para a formação de pastagens mistas de gramíneas e leguminosas deve-se à melhoria da fertilidade do solo pelas leguminosas e à sustentabilidade da pastagem pela deposição de liteira de melhor qualidade. A deposição anual de folhas e ramos, em um bosque de sabiá em Itambé, PE, foi de $15.167 \mathrm{~kg}$ de MO.ha ${ }^{-1}$ e $3.373 \mathrm{~kg}$ de MO.ha ${ }^{-1}$, respectivamente, sendo a proporção de folhas entorno de $87 \%$ do total da liteira (FREIRE, 2008).

A deposição e estoque de serapilheira de sabiá foram estimados em 7.830,44 kg.ha- ${ }^{-1} \cdot$ ano $^{-1}$ e 8.906,9 kg.ha- ${ }^{-1}$, respectivamente, com a fração folha dominante (FERREIRA et al., 2007). No entanto, a produção de liteira foi semelhante entre pastagens de gramíneas puras ou consorciadas (15 a $18 \mathrm{t} \mathrm{MS} \mathrm{ha-1}$. ano $^{-1}$ ), mas a leguminosa aumentou a concentração de $\mathrm{N}$ na liteira e a quantidade de $\mathrm{N}$ reciclada (CANTARUTTI, 1996). A massa de liteira contribui para a ciclagem de nutriente, mas isso depende da sua qualidade.

Tabela 5 - Características de raízes e liteira de plantas de sabiá submetidas à adubação fosfatada, nos períodos antes e depois da poda, em Itambé, PE

Table 5 - Root and litter characteristics of Sabiá plants submitted to phosphorus fertilization before and after pruning, Itambé-PE

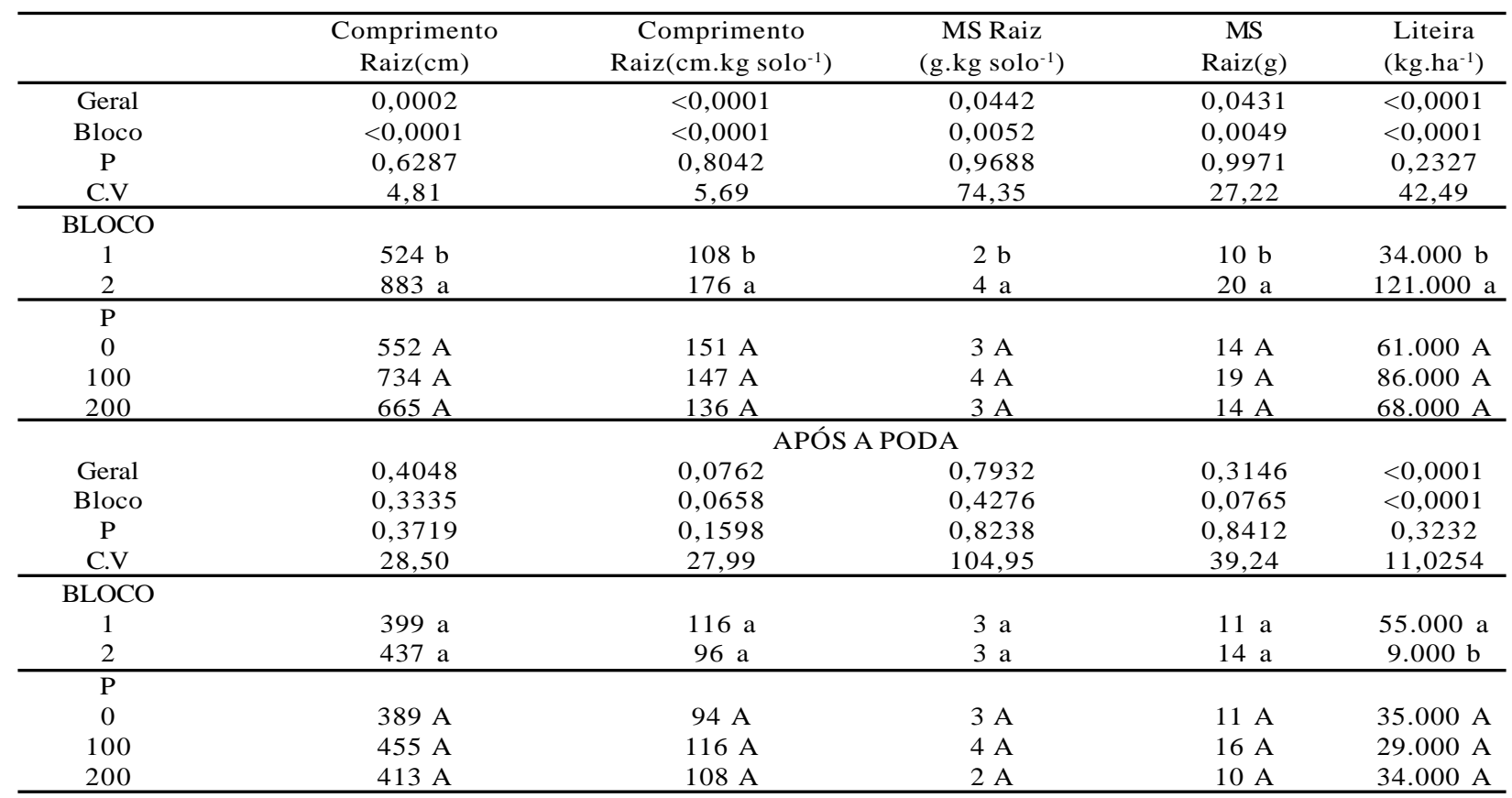

Para P, médias seguidas de igual letra maiúscula não diferem pelo teste de Tukey $(\mathrm{P}>0,05)$. Para bloco, médias seguidas de igual letra minúscula não diferem entre si, pelo teste $\mathrm{F}(\mathrm{P}>0,05)$. For $\mathrm{P}$, means followed by the same capital letter do not differ by the Tukey test $(\mathrm{P}>0.05)$. For block, means followed by the same lower case letter do not differ by the $\mathrm{F}$ test $(\mathrm{P}>0.05)$. 
A adubação fosfatada (0, 100, $200 \mathrm{~kg} \cdot \mathrm{ha}^{-1}$ de $\left.\mathrm{P}_{2} \mathrm{O}_{5}\right)$ no período em que antecede a poda não mostrou efeito sobre a massa seca de nódulos $\mathrm{mg} / \mathrm{kg}$ solo. Stamford e Silva (2000) observaram que a falta de efeito da calagem sobre o peso seco de nódulos de plantas de sabiá foi atribuída ao fato de a calagem poder promover desequilíbrio microbiano no solo e aumento dos actinomicetos, o que pode favorecer a produção de antibióticos na rizosfera e prejudicar a nodulação.

Para número de nódulos e nódulos. $\mathrm{kg}^{-1}$ de solo houve efeito significativo da adubação, no período que antecede a poda, podendo ser explicado pela umidade do solo, essencial para o desenvolvimento e atividade dos microrganismos responsáveis pelo processo de nodulação, assim como a época da coleta, densidade do solo e precipitação pluviométrica da ocasião (Figura 1). Isso concorda com estudos sobre efetividade da inoculação com rizóbio e fungos micorrízicos arbusculares em mudas de sabiá, submetidas a diferentes níveis de fósforo (BURITY et al., 2000). A adubação fosfatada não afetou a nodulação do composto do lixo urbano suplementado com fósforo e da inoculação com Bradyrhizobium em Caupi (SANTOS et al., 1992). Mas a adubação fosfatada aumenta a biomassa da parte aérea, sistema radicular e nodulação (KROLOW et al., 2004). Em estudos realizados com adubação fosfatada no desenvolvimento da parte aérea e sistema radicular de plantas de andiroba (Carapa guianensis Aubl.), não foi observado seu efeito (NEVES et al., 2004).

A adubação fosfatada não afetou as variáveis estudadas no período após a poda da parte aérea da planta, o que pode estar relacionado à necessidade da planta em recompor sua parte aérea para disponibilizar maior quantidade de energia através da fotossíntese, ou pela baixa disponibilidade de chuva nesse período. No entanto, a maioria dos solos tropicais necessita de fornecimento de fósforo por apresentarem deficiências deste e sofre efeito da atividade da nitrogenase pelo dispêndio energético promovido pela atividade da fixação biológica de nitrogênio (STRALIOTTO et al., 2003).

Tabela 6 - Características de nódulos de plantas de sabiá submetidas à adubação fosfatada, nos períodos antes e depois da poda, em Itambé, PE

Table 6 - Nodule characteristics of Sabiá plants submitted to phosphorus fertilization before and after pruning, Itambé-PE

\begin{tabular}{|c|c|c|c|c|}
\hline & MS Nódulos (g) & MS Nódulos g.kg solo-1 & $\mathrm{N}^{\circ}$ Nódulos & $\mathrm{N}^{\circ}$ Nódulos (un.kg solo ${ }^{-1}$ ) \\
\hline & \multicolumn{4}{|c|}{ Antes da Poda } \\
\hline Geral & $<0,0001$ & 0,0071 & 0,0031 & 0,0042 \\
\hline Bloco & $<0,0001$ & 0,0024 & 0,0044 & 0,0051 \\
\hline $\mathrm{P}$ & 0,0547 & 0,1857 & 0,0342 & 0,0440 \\
\hline C.V & 49,83 & 168,43 & 42,15 & 39,52 \\
\hline \multicolumn{5}{|l|}{$\overline{\mathrm{BLOCO}}$} \\
\hline 1 & $0,0012 \mathrm{~b}$ & $0,0030^{\mathrm{a}}$ & $14 \mathrm{a}$ & $3 \mathrm{a}$ \\
\hline 2 & $0,0010 \mathrm{a}$ & $0,0001 b$ & $3 \mathrm{~b}$ & $0,54 \mathrm{~b}$ \\
\hline \multicolumn{5}{|c|}{, } \\
\hline 0 & $0,00020 \mathrm{~A}$ & $0,0002^{a}$ & $2 \mathrm{~B}$ & $0,40 \mathrm{~B}$ \\
\hline 100 & $0,00076 \mathrm{~A}$ & $0,0007^{\mathrm{a}}$ & $15 \mathrm{~A}$ & $3 \mathrm{~A}$ \\
\hline 200 & $0,00099 \mathrm{~A}$ & $0,0099^{\mathrm{a}}$ & $6 \mathrm{AB}$ & $1 \mathrm{~A}$ \\
\hline & \multicolumn{4}{|c|}{ Após a Poda } \\
\hline Geral & 0,2220 & 0,4218 & 0,0997 & 0,1308 \\
\hline Bloco & 0,2577 & 0,7079 & 0,1428 & 0,3333 \\
\hline $\mathrm{P}$ & 0,2078 & 0,2763 & 0,1203 & 0,0941 \\
\hline C.V & 0,0756 & 168,01 & 89,07 & 43,77 \\
\hline \multicolumn{5}{|c|}{ BLOCO } \\
\hline 1 & $0,00090 a$ & $0,0009^{a}$ & $2 a$ & $1 \mathrm{a}$ \\
\hline 2 & $0,00071 \mathrm{a}$ & $0,0007^{\mathrm{a}}$ & $7 \mathrm{a}$ & $8 \mathrm{a}$ \\
\hline \multicolumn{5}{|l|}{$\bar{P}$} \\
\hline 0 & $0,00034 \mathrm{~A}$ & $0,0003^{\mathrm{a}}$ & $1 \mathrm{~A}$ & $0,3 \mathrm{~A}$ \\
\hline 100 & $0,00098 \mathrm{~A}$ & $0,0010^{\mathrm{a}}$ & $6 \mathrm{~A}$ & $2 \mathrm{~A}$ \\
\hline 200 & $0,0011 \mathrm{~A}$ & $0,0011^{\mathrm{a}}$ & $7 \mathrm{~A}$ & $2 \mathrm{~A}$ \\
\hline
\end{tabular}

Para $\mathrm{P}$, médias seguidas de igual letra maiúscula não diferem entre si, pelo teste de Tukey $(\mathrm{P}>0,05)$; para bloco, médias seguidas de igual letra minúscula não diferem entre si, pelo teste $\mathrm{F}(\mathrm{P}>0,05)$. For $\mathrm{P}$, means followed by the same capital letter do not differ by the Tukey test $(\mathrm{P}>0.05)$, for block, means followed by the same lower case letter do not differ by the $\mathrm{F}$ test $(\mathrm{P}>0.05)$.

R. Árvore, Viçosa-MG, v.33, n.2, p.237-244, 2009 
A falta de efeito da adubação fosfatada neste trabalho provavelmente se deve à baixa mobilidade de fósforo no solo e do fato de a adubação ter sido centralizada na parcela experimental, o que aumentou a competição entre as demais plantas.

\section{CONCLUSÃO}

A poda da parte aérea da sabiá (Mimosa caesalpiniifolia) reduz o aparecimento dos nódulos.

A adubação fosfatada não afetou a ausência ou presença dos nódulos, bem como o comprimento de raízes de plantas de sabiá.

\section{REFERÊNCIAS}

ALMEIDA, A. C. S. et al. Avaliação bromatológica de espécies arbóreas e arbustivas de pastagens em três municípios do estado de Pernambuco. Acta Scientiarum Animal Sciences, v.28, n.1, p.1-9, 2006.

ALMEIDA, R. T.; VASCONCELOS, I.; NESS, R. L. L. Infecção micorrízica vesículo-arbuscular e nodulação de leguminosas arbóreas do Ceará, Brasil. Ciência Agronômica, v.17, n.1, p.89-97, 1986.

ALVES, E. U. et al. Dormência e desenvolvimento de sementes de sabiá (Mimosa caesalpiniifolia Benth). Revista Árvore, v.28, n.5, p.655-662, 2004.

BARBERI, A. et al. Nodulação em leguminosas florestais em viveiros no sul de Minas Gerais. Cerne, v.4, n.1, p.145-153, 1998.

BURITY, H. A. et al. Efetividade da inoculação com rizóbio e fungos micorrízicos arbusculares em mudas de Sabiá submetidas a diferentes níveis de fósforo. Pesquisa Agropecuária

Brasileira, v.35, n.4, p.801-807, 2000.

CANTARUTTI, R. B. et al. The effect of grazing intensity and the presence of a forage legume on nitrogen dynamics in Brachiaria pastures in the Atlantic forest region of the south of Bahia, Brazil. Nutrient Cycling in

Agroecosystems, v.64, n.3, p.257-271, 2002.

COSTA, G. S. et al. Aporte de nutrientes pela serapilheira em uma área degradada e revegetada com leguminosas arbóreas. Revista Brasileira de Ciências do Solo, v.28, n.5, p.919-927, 2004.
COMPANHIA PERNAMBUCANADO MEIO AMBIENTE - CPRH. Diagnóstico Sócioambiental do Litoral Norte de Pernambuco. Recife: 2003. 214p.

DIABATE, M. et al. Occurrence of nodulation in unexplored leguminous trees native to the West African tropical rainforest and inoculation response of native species useful in reforestation. New Phytologist, v.166, n.1, p.231-239, 2005.

DULORMNE, M. et al. Nitrogen-fixation dynamics in a cut-and-carry silvopastoral system in the subhumid conditions of Guadeloupe, French Antilles. Agroforestry Systems, v.59, n.2, p.121-129, 2003.

FERREIRA, R. L. C. et al. Deposição e acumulo de matéria seca e nutrientes em serapilheira em um bosque de Sabiá (Mimosa caesalpiniifolia Benth.). Revista Árvore, v.31, n.1, p.7-12, 2007.

FREIRE, J. L. Deposição, composição química e decomposição de liteira em um bosque de Sabiá (Mimosa caesalpiniifolia, Benth). 2008. 69f. Dissertação (Mestrado em Zootecnia) - Universidade Federal Rural de Pernambuco, Recife, 2008.

GONÇALVES, C. A.; GOI, S. R.; JACOB NETO, J. Crescimento e nodulação do Ingá Marginata em resposta a adição de nitrogênio fósforo e inoculação com rizóbio. Floresta e Ambiente. v.6, n.1, p.118-126, 1999.

GROSSMAN, J. M. et al. An assessment of nodulation and nitrogen fixation in inoculated Inga oerstediana, a nitrogen-fixing tree shading organically grown coffee in Chiapas, Mexico. Soil Biology and Biochemistry, v.38, n.4, p.769-784, 2006.

JACOMINE, P. K. T. Evolução do conhecimento sobre solos coesos no Brasil. In: WORKSHOP COESÃO EM SOLOS DOS TABULEIROS COSTEIROS, Aracaju, 2001. Anais... Aracaju: Embrapa Tabuleiros Costeiros, 2001. p.19-46.

KROLOW, R. H. et al. Effect of phosphorus and potassium on development and nodulation of three cool season annual legumes. Revista Brasileira Zootecnia, v.33, n.6, p. 255-260, 2004.

R. Árvore, Viçosa-MG, v.33, n.2, p.237-244, 2009 
LORENZI, H. Árvores brasileiras: manual de identificação e cultivo de plantas arbóreas nativas do Brasil. 3.ed. Nova Odessa: Instituto Plantarum, 2000. v.1.351p.

MOREIRA, F. M. S. Nitrogen-fixing Leguminosaenodulating bacteria. In: MOREIRA, F. M. S.; SIQUEIRA, J. O.; BRUSSAARD, L. Soil biodiversity in Amazonian and other brazilian ecosystems. Wallingford: CAB International Publishing, 2006. p.237-270.

MOREIRA, F. M. S.; PEREIRA, E. G.

Microsymbionts: rhizobia. In: SWIFT, M.; BIGNELL, D. Standard methods for assessment of soil biodiversity and land use practice. Bogor: International Centre for Research in Agroforestry, 2001.p.19-24.

NEVES, O. S. C. et al. Crescimento, produção de matéria seca e acúmulo de $\mathrm{N}, \mathrm{P}, \mathrm{K}, \mathrm{Ca}, \mathrm{Mg}$ e $\mathrm{S}$ na parte aérea de mudas de andiroba (Carapa guianensis Aubl.) cultivadas em solo de várzea, em função de diferentes doses de fósforo. Revista Árvore, v.28, n.3, p.343-349, 2004.

RESENDE, A. V. et al. Crescimento Inicial de espécies florestais de diferentes grupos sucessionais em resposta a doses de fósforo. Pesquisa Agropecuária Brasileira, v.34, n.11, p.2071-2081, 1999.

SANTOS, C. E. R. S.; STANFORD, N. P.; SANTOS, D. R. Efeito do composto do lixo urbano suplementado com fósforo e da inoculação com Bradyrhizobium em Caupi. Revista Brasileira Ciência do Solo, v.16, n.1, p.25-30, 1992.
SAS INSTITUTE. SAS/STAT User's guide. Version 8. Cary: 1999. 1464p.

SOUZA, L. S.; COGO, N. P.; VIEIRA, S. R. Variabilidade de propriedades físicas e químicas do solo em pomar cítrico. Revista Brasileira de Ciência do Solo, v.21, n.3, p.367-372, 1997.

STAMFORD, N. P.; SILVA, R. A. Efeito da calagem e inoculação de Sabiá em solo da mata úmida e do semi-árido de Pernambuco.

Pesquisa Agropecuária Brasileira, v.35, n.5, p.222-227, 2000.

STRALIOTTO, R. et al. Diversity of rhizobia nodulating common beans (Phaseolus vulgaris L.) isolated from brazilian tropical soils. Anais da Academia Brasileira de Ciências, v.71, n.3, p.531-543, 1999.

VASCONCELOS, I. et al. Comportamento de 13 estirpes de Rhizobium sp. em simbiose com Sabiá, (Mimosa caesalpiniifolia Benth). Ciências Agronômicas, v. 15, n.1/2, p.133-138, 1984.

WOLDE-MESKEL, E. et al. Nodulation status of native woody legumes and phenotypic characteristics of associated rhizobia in soils of southern Ethiopia. Biology and Fertility of Soils, v.40, n.1, p.55-66, 2004. 